Annales Geophysicae (2001) 19: 633-641 C European Geophysical Society 2001

\title{
Astrid-2 and ground-based observations of the auroral bulge in the middle of the nightside convection throat
}

\author{
G. T. Marklund ${ }^{1}$, T. Karlsson ${ }^{1}$, P. Eglitis ${ }^{2}$, and H. Opgenoorth ${ }^{2}$ \\ ${ }^{1}$ Division of Plasma Physics, Alfvén Laboratory, Royal Institute of Technology, SE 10044 Stockholm, Sweden \\ ${ }^{2}$ Swedish Institute of Space Physics, Uppsala, Sweden
}

Received: 3 July 2000 - Revised: 25 September 2000 - Accepted: 26 September 2000

\begin{abstract}
Results concerning the electrodynamics of the nightside auroral bulge are presented based on simultanous satellite and ground-based observations. The satellite data include Astrid-2 measurements of electric fields, currents and particles from a midnight auroral oval crossing and Polar UVI images of the large-scale auroral distribution. The ground-based observations include STARE and SuperDARN electric fields and magnetic records from the Greenland and MIRACLE magnetometer network, the latter including stations from northern Scandinavia north to Svalbard. At the time of the Astrid-2 crossing the ground-based data reveal intense electrojet activity, both to the east and west of the Astrid-2 trajectory, related to the Polar observations of the auroral bulge but not necessarily to a typical substorm. The energetic electron fluxes measured by Astrid- 2 across the auroral oval were generally weak being consistent with a gap observed in the auroral luminosity distribution. The electric field across the oval was directed westward, intensifying close to the poleward boundary followed by a decrease in the polar cap. The combined observations suggests that Astrid-2 was moving close to the separatrix between the dusk and dawn convection cells in a region of low conductivity. The constant westward direction of the electric field across the oval indicates that current continuity was maintained, not by polarisation electric fields (as in a Cowling channel), but solely by localized up- and downward field-aligned currents in good agreement with the Astrid-2 magnetometer data. The absence of a polarisation electric field and thus of an intense westward closure current between the dawn and dusk convection cells is consistent with the relatively weak precipitation and low conductivity in the convection throat. Thus, the Cowling current model is not adequate for describing the electrodynamics of the nightside auroral bulge treated here.
\end{abstract}

Correspondence to: G. T. Marklund

(marklund@plasma.kth.se)
Key words. Ionosphere (auroral ionosphere; electric fields and currents; plasma convection)

\section{Introduction}

The nightside auroral bulge is the common name for the extensive region of auroral activity that develops in the midnight sector due to a massive energy input from the magnetospheric tail during the main phase of a substorm. The westward travelling surge, in the northwest part of the bulge, is the most spectacular of the large-scale auroral displays and believed to represent the optical signature of the westward part of the substorm expansion region near magnetic midnight (Akasofu et al., 1965, 1966). The northeastern boundary of the auroral bulge, sometimes develops into Omega bands (Opgenoorth et al., 1983; Amm, 1996; Pulkkinen et al., 1998), which are large-scale periodic auroral vortices. The head of the surge has been shown to be associated with converging electric fields, driving inward-directed Pedersen currents which connect to an intense upward field-aligned current (Inhester et al., 1981; Opgenoorth et al., 1983).

The large-scale current flow associated with the auroral bulge is often described by an intense westward electrojet, such as the substorm current wedge, connecting distributed downward FACs in the eastern part of the bulge to an upward FAC in the surge head. This is, in principal, the same as the type II current system suggested by Boström (1964) and it has become, more or less, the generally accepted picture of the large-scale ionospheric current closure associated with the auroral bulge (e.g. McPherron, 1973; Kamide and Akasofu, 1975). Since the Cowling mechanism is very efficient for producing an intense electrojet, it has often been used in connection with the substorm current wedge (e.g. Inhester et al., 1981; Weimer et al., 1994). The dynamics of the surge and in particular the expansion of the north- and 


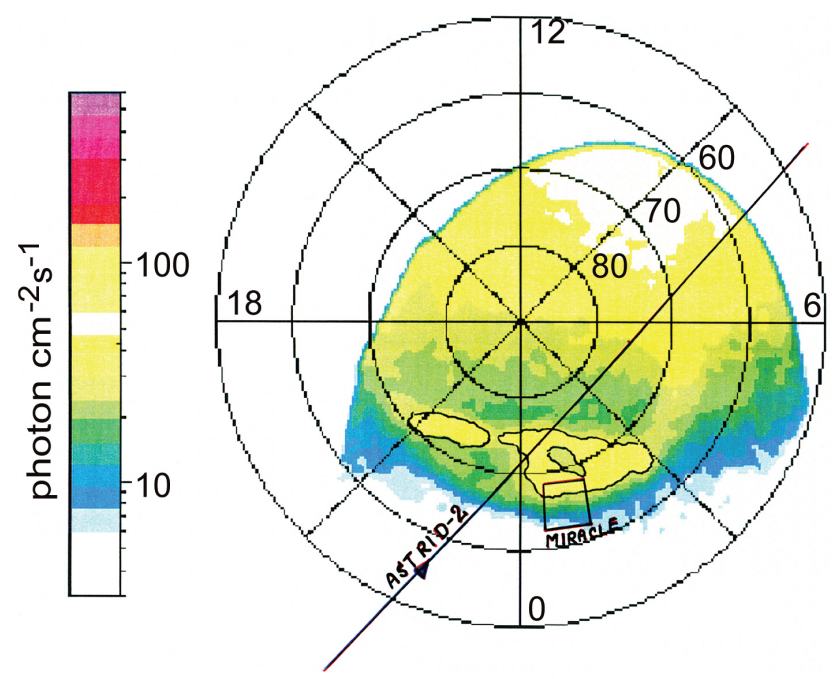

Fig. 1. Polar UV image of a nightside auroral bulge observed on 7 May 1999 at 22:22 UT. Superposed on the image are the footpoint of the Astrid-2 orbit (2033) and the field-of-view of the MIRACLE ground-based network in northern Scandinavia.

westward conductivity gradients of the surge and associated pulsations, have been studied by Rothwell et al. $(1984,1986)$ based on the Cowling channel model. The westward expansion of the dawn convection streamlines associated with the highly conducting surge region have also been demonstrated in model simulations by Kan et al. (1984) and Marklund et al. (1985). The westward electric field associated with this protrusion was taken as a support of the Cowling model of the surge region.

Arguments against the Cowling model scenario have recently been presented by Marklund et al. (1998). By studying Freja observations from a crossing directly through the surge head, they found evidence that the upward surge current was closed, to a large extent, by downward FACs in the near vicinity of the surge head. A numerical simulation model has been used to reconstruct the surge electric fields and currents for this particular event and for another surge event presented by Weimer et al. (1994) showing a much better agreement with the electric field measurements when the upward surge current was closed locally than when it was closed by remotely distributed downward currents (manuscript in preparation). Thus, the Freja observations as well as the numerical simulation results indicate a much weaker connection current between the eastern and the western part of the bulge than usually anticipated.

Another argument against the Cowling current model is that it is often applied to the auroral bulge as a whole although the region which best should meet the criteria of being a highly conducting channel is the region near the poleward edge of the pre-midnight bulge, typically having the highest concentration of intense auroras (see Fig. 11 of Fujii et al., 1994). This region is typically associated with a net upward current and a westward Hall current driven by a southward spike-like electric field, located poleward of the oval boundary, and thus not inside the high-conductive region as in a Cowling channel. Thus, the poleward part of the bulge often covered by intense auroras, is not consistent with the Cowling channel characteristics.

A fundamental question in the electrodynamics of the auroral bulge is thus how, and to what extent, the dawn and dusk convection cells are interconnected by enhanced ionospheric currents, such as the substorm current wedge. What is the relative role of localised and remote closure of the upward surge current? Is the Cowling current model really applicable to the bulge electrodynamics? These questions are addressed in the present study which uses satellite observations by Astrid-2 and Polar and ground-based observations of plasma drifts and currents during an event characterised by significant auroral and electrojet activity in the midnight sector around 22 UT on 7 May 1999.

\section{Observations}

\subsection{Overview of observations}

Figure 1 shows a polar plot (geomagnetic latitude and magnetic local time) of the nightside auroral distribution as viewed by the Polar UV-imager experiment on 7 May 1999 at 22:22 UT, the ionospheric footpoint of the Astrid-2 orbit number 2033 and the field-of-view of the MIRACLE groundbased facilities in northern Scandinavia. The Astrid-2 orbit at an altitude of $1000 \mathrm{~km}$ is seen to cross a gap in the auroral distribution separating it into a premidnight and a postmidnight part. The AE index for this event remained essentially at a fairly constant level of 200-250 NT between 20 and 24 UT. The Polar UVI-images also revealed the presence of an extended region of auroral activity near local midnight lasting for several hours between 21:30 UT and 24 UT.The field of view of the MIRACLE ground-based network covered at this time the equatorward portion of the auroral oval near 01:00 MLT. Figure 2a shows plasma drift vectors and equivalent current vectors representative for 22:15 UT, shortly before the Astrid-2 crossing. The westward electrojet, driven by a south- to southwestward electric field (corresponding to the east- to southeastward $\boldsymbol{E} \times \boldsymbol{B}$ drift vectors seen at the top), started to form shortly after 22 UT. Figure $2 b$ shows the electrojet at 22:23 UT when it had reached its maximum intensity. No plasma drift vectors are seen at this time which is likely due to an electric field decrease below the threshold of detectability $(E<15 \mathrm{mV} / \mathrm{m})$. Such a decrease in the electric field is typically associated with an increase in the electron precipitation and thus also the ionospheric conductivity. The equivalent currents deduced from the Svalbard and Bjørnøya magnetometer data (not shown here) are for this particular time pointing northeast as is characteristic of the dawn convection cell poleward of the convection reversal.

Figure 3 shows magnetometer recordings from the Greenland coastal magnetometer array operated by the Danish Meteorological Institute, and the Raven Skiway (ice cap) magnetometer operated by SPRL, University of Michigan. The 

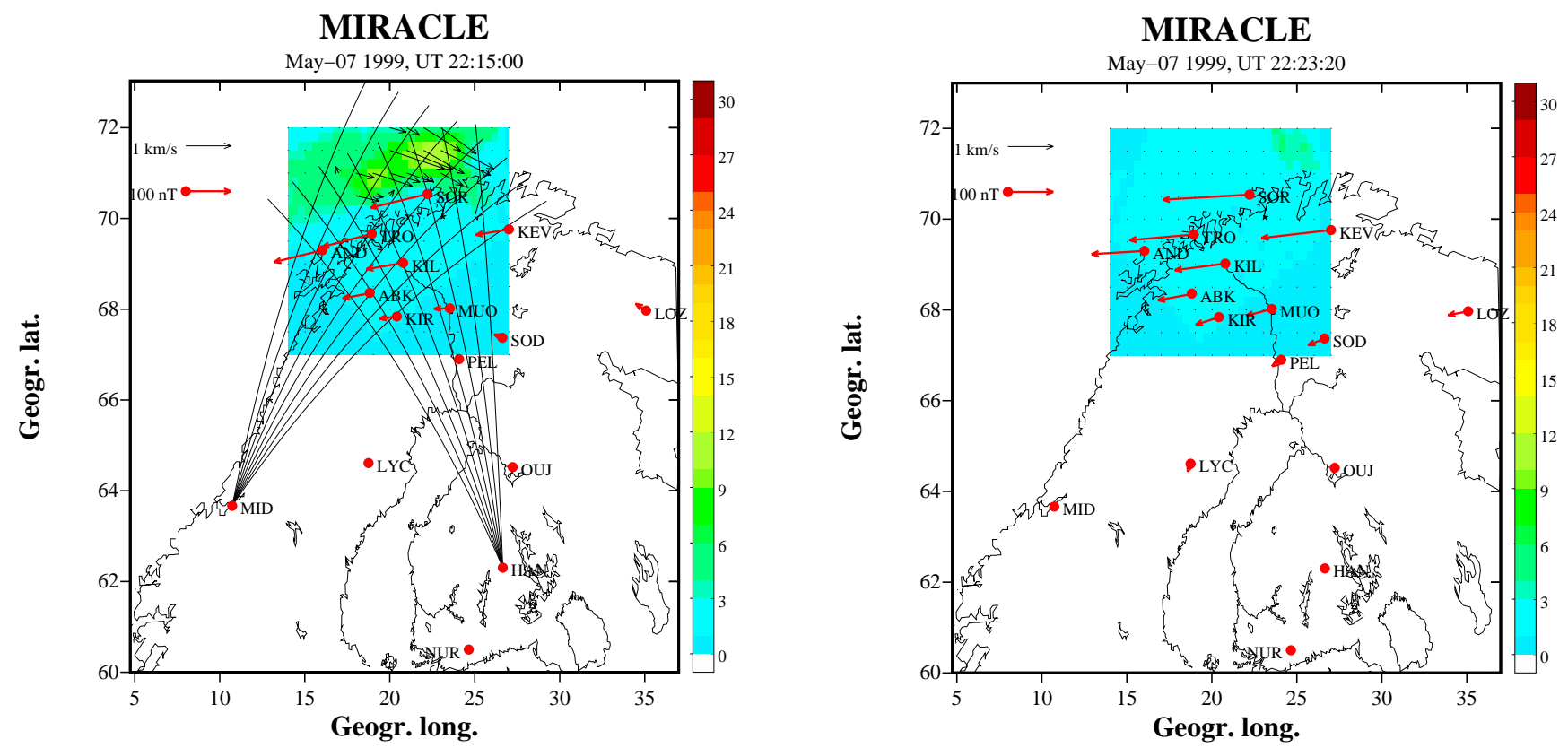

Fig. 2. Plasma drift vectors and equivalent currents deduced from the MIRACLE observations at 22:15:00 UT (a) and at 22:23:20 UT (b).
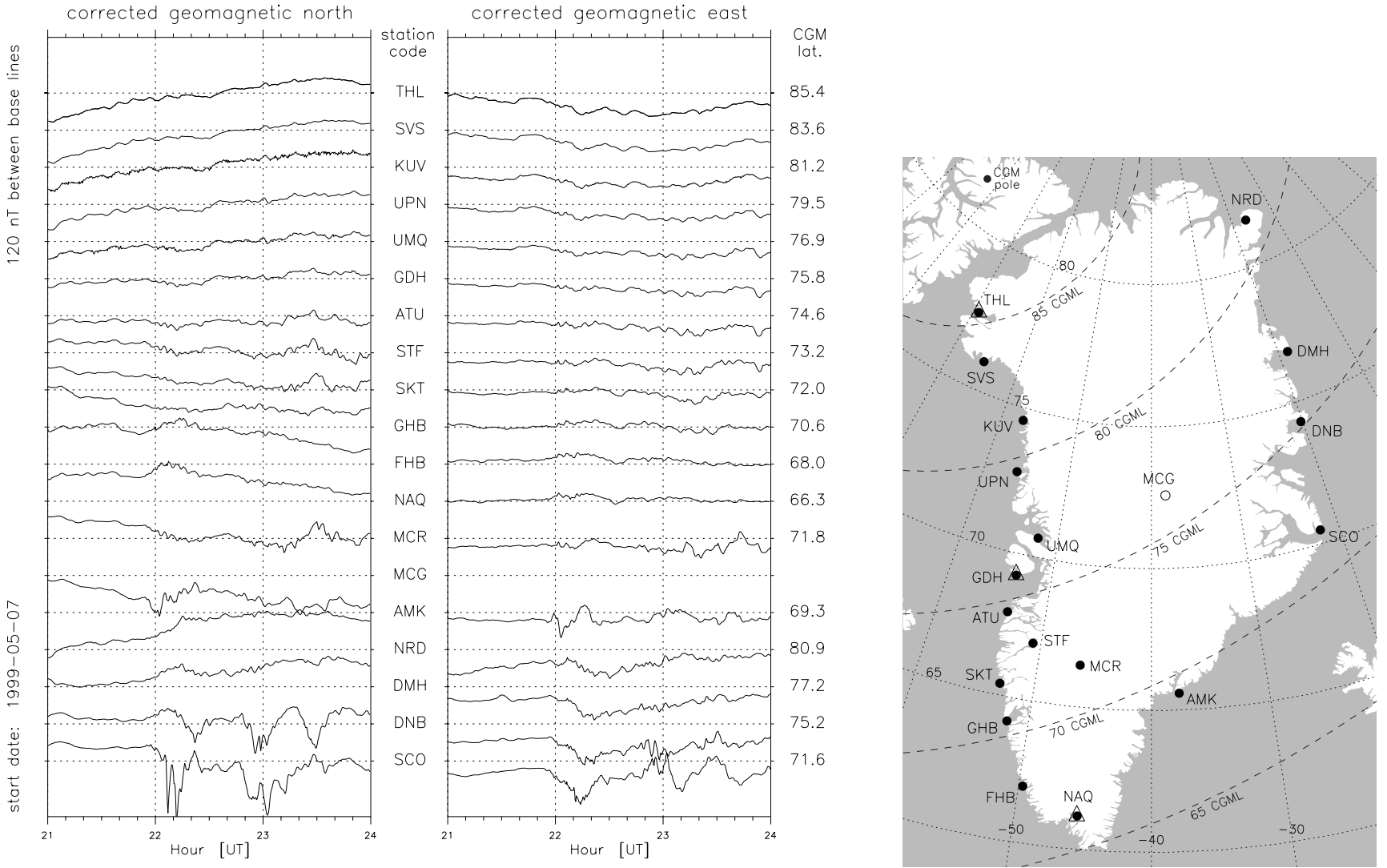

Fig. 3. Greenland magnetometer data given in corrected geomagnetic north and east coordinates for the time period 21-24 UT on 7 May 1999 (a) and a map of the locations of the magnetometer stations (b).

left and right panels of Fig. 3a display the corrected geomagnetic north and east components, respectively. Figure
$3 \mathrm{~b}$ shows the corresponding locations of the different magnetometer stations. Shortly after 22 UT the southernmost 


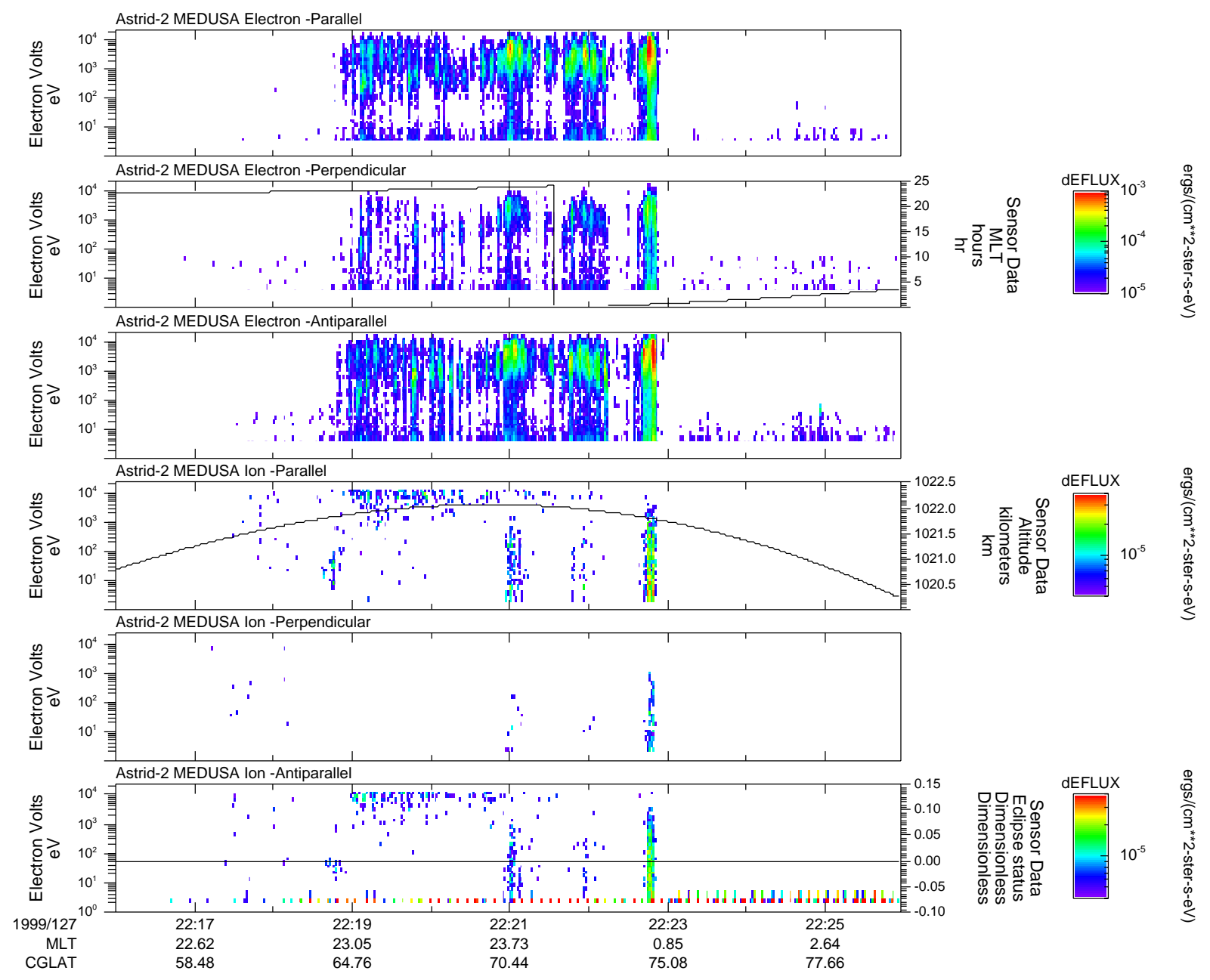

Fig. 4. Energy time spectrograms of electrons and ions measured by the Astrid-2 particle instrument during the nightside auroral oval crossing between 22:16 UT and 22:26 UT on 7 May 1999. For more information see text.

stations of the Eastern chain of magnetometers, in particular Daneborg (DNB) and Ittoqqortoormiit (SCO) register negative bays in both the northward and eastward components. The horizonthal B vector is directed towards southwest reaching its peak value first at Ittoqqortoormiit around 22:12 UT and later, around 22:20 UT, at Daneborg. The latter peak thus corresponds in time to the Astrid- 2 crossing of the midnight auroral oval. This implies a poleward motion of the centre of the nortwestward pointing equivalent current. Considering the local time of the observations, around 22 MLT, it is likely that this equivalent current flows poleward of the dusk convection reversal. The westcoast chain of magnetometers (THL to FHB) reveal around this time relatively weak electrojet activity with a westward electrojet to the north and an eastward to the south, the reversal being located around $73^{\circ}$ corrected geomagnetic latitude.

To summarize these observations it is clear that at the time of the Astrid-2 oval crossing near local midnight intense electrojet activity was observed both eastward and westward of the Astrid-2 trajectory with typical characteristics of the substorm-enhanced dawn and dusk convection cells, respectively.

\subsection{Astrid-2 observations}

Figure 4 shows energy time spectrograms of electrons and ions observed by Astrid- 2 over the nightside auroral oval between 22:16 UT and 22:26 UT. From top to bottom are shown electron fluxes measured in the direction roughly parallel to $\mathrm{B}$, perpendicular to $\mathrm{B}$ and antiparallel to $\mathrm{B}$, followed by ions for the same directions. The entrance into the oval, as judged from the electron data, occurred at 22:18:40 UT and the exit occurred around 22:22:40 UT. In the equatorward half of the oval the fluxes are seen to be fairly weak whereas the poleward half contains three regions of more enhanced electron energy flux, the narrow region near the poleward edge being most intense with characteristic energies between 5 and $10 \mathrm{keV}$. These data are consistent with the auroral luminosity gap visible in the equatorward half of the oval in Fig. 1.

Figure 5 shows electric field, magnetic field and plasma density observations by Astrid-2 between 22:16 UT and 22:26 UT. From top to bottom are shown the geomagnetic eastward and southward components of the electric field, the corresponding components of the magnetic field, and the 


\section{Astrid-2 data 1999-05-07 (DOY 127)}

Orbit 2033
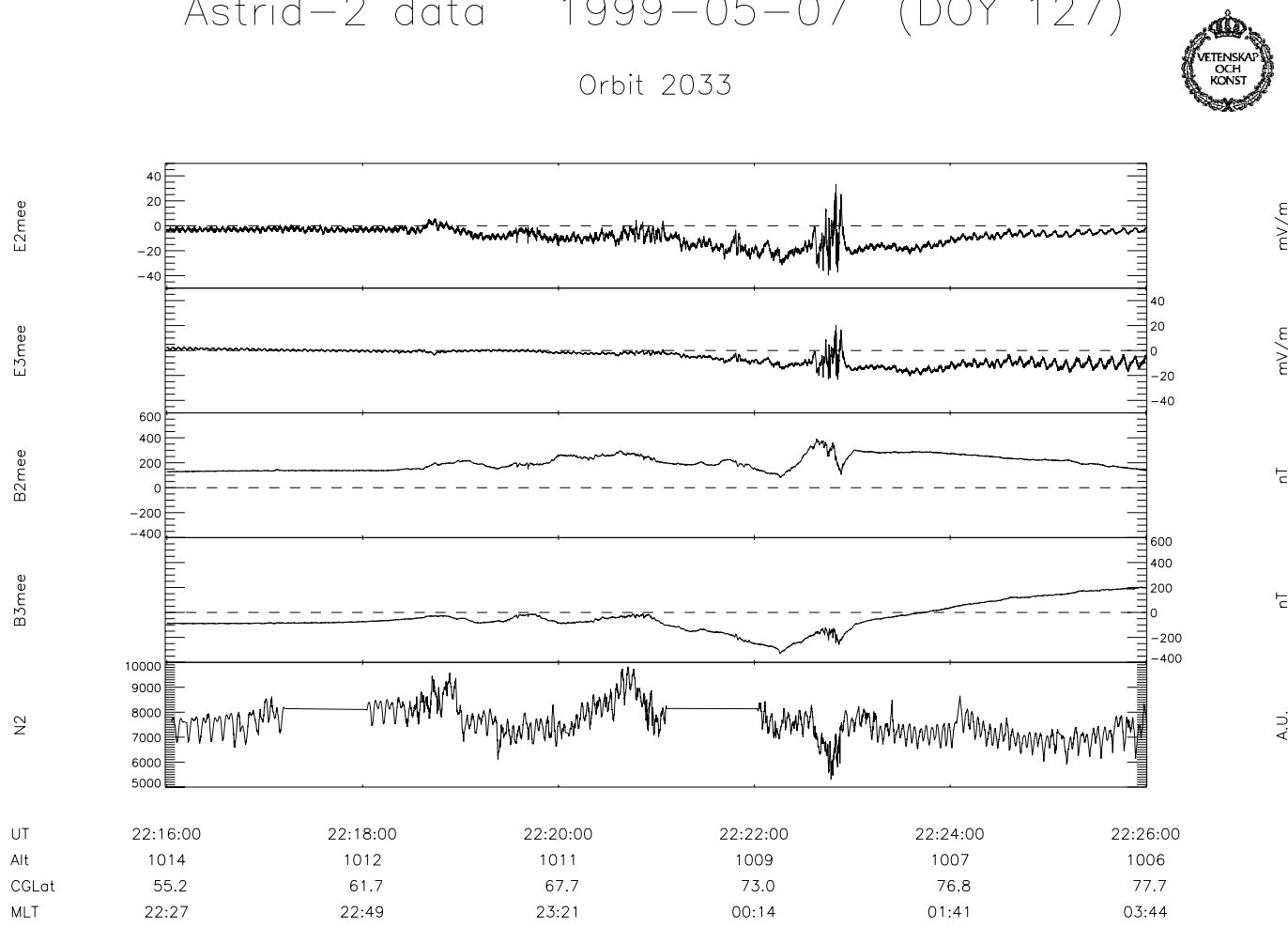

Fig. 5. Electric field, magnetic field and plasma density measured by Astrid-2 for the same time interval as in Fig. 4. The panels show from top to bottom the geomagnetic east and west components of the electric field and of the magnetic field, respectively, and the plasma density measured by the Langmuir probe.

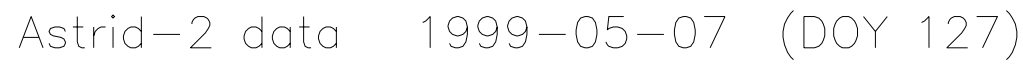

Orbit 2033
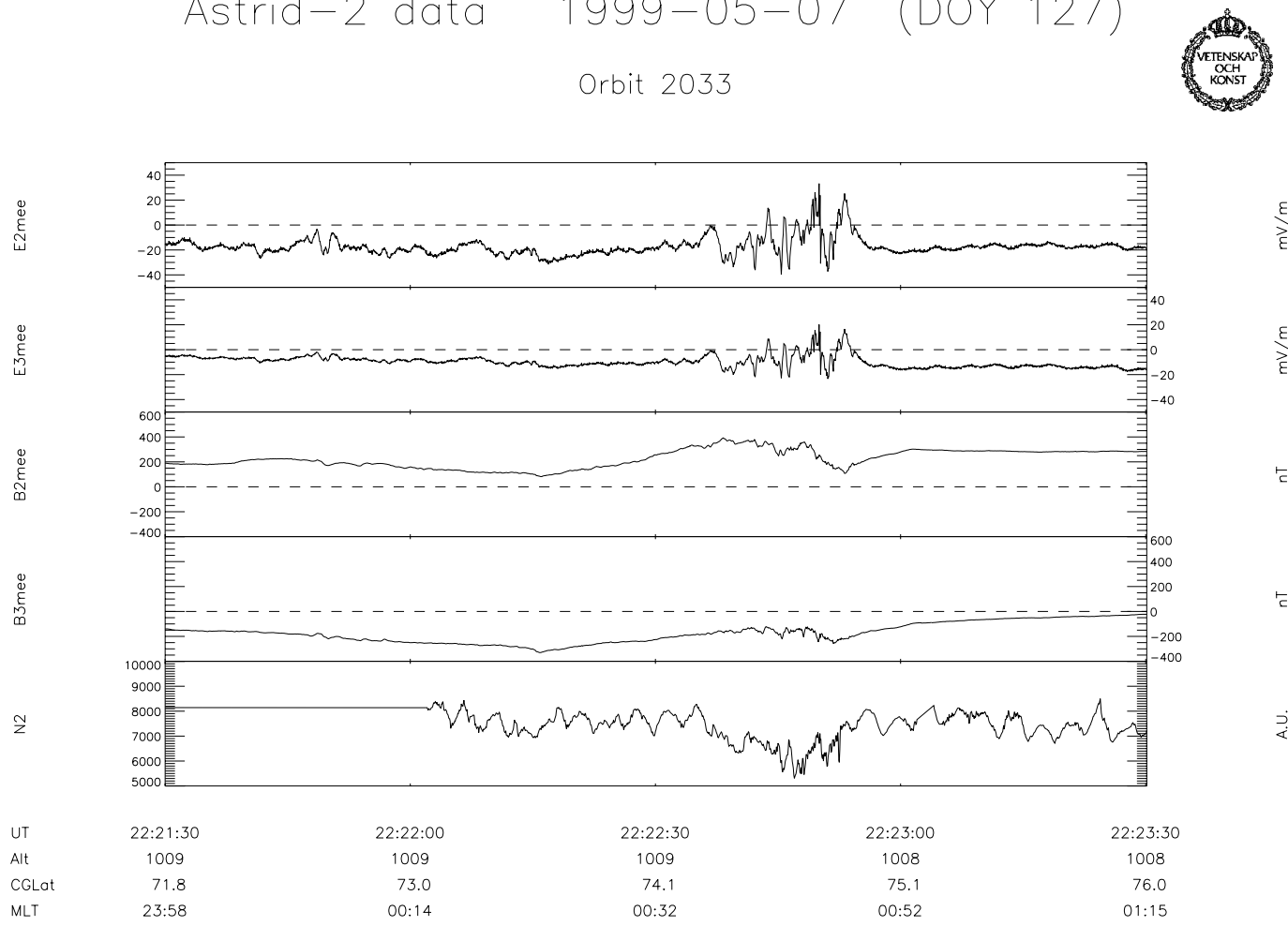

Fig. 6. Close up view of the electric field, magnetic field and plasma density data between 22:21:30 UT and 22:23:30 UT when Astrid-2 crossed the narrow precipitation region near the poleward auroral oval boundary. 


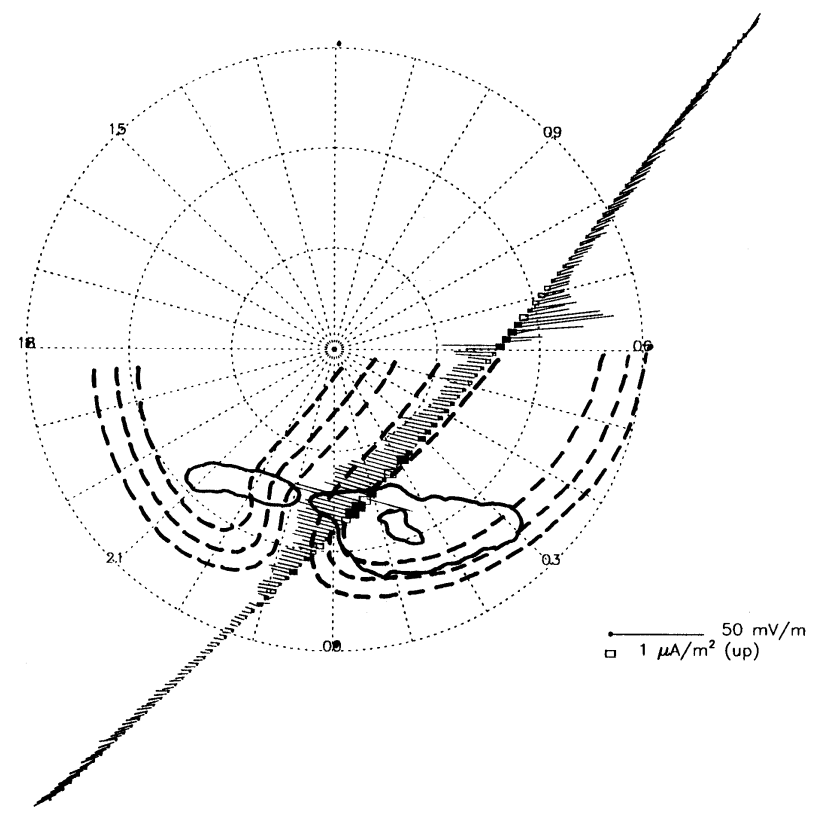

Fig. 7. Summary of the observations. The electric and magnetic field data along the footpoint of the Astrid-2 orbit are represented by electric field vectors and by calculated upward and downward field-aligned currents (open and solid squares, respectively). The dotted lines represent equipotential contours that are consistent with the Astrid-2 and STARE electric field data and with the directions of the electrojets inferred from the magnetometer data on Greenland, Svalbard, Bjørnøya and northern Scandinavia.

plasma density data from the Langmuir probe. Equatorward of the oval both electric field components are close to zero. For the equatorward half of the oval, between 22:18:40 UT and 22:21:00 UT, the electric field is seen to be very weak (around $5 \mathrm{mV} / \mathrm{m}$ ) and directed westward. In the poleward half, shown in more detail in Fig. 6, the electric field is generally more intense and more structured. Between 22:22:35 UT and 22:22:55 UT, the electric field is very irregular with large spikes. The field is westward in the equatorward part of the interval, fluctuating between westward and eastward in the central part (but with an average westward direction) and is eastward at the poleward boundary of the oval. This irregular region coincides with a negative slope in the eastward magnetic field component (indicative of an upward field-aligned current), with a region of intense energetic precipitation seen in Fig. 4 and with a weak plasma density cavity of around $20 \%$. The upward current sheet is seen to be balanced by two surrounding downward current sheets, the closure currents being, on the average, converging Hall currents. The fluctuations in the electric and magnetic field data are evidence of Alfvénic activity, the fluctuations having a characteristic frequency of around $0.4 \mathrm{~Hz}$, the $\Delta E / \Delta B$ ratio corresponding to an Alfvén velocity of about $1000 \mathrm{~km} / \mathrm{s}$ which is consistent with a plasma density of about $7000 \mathrm{~cm}^{-3}$. Another indication of Alfvén wave activity in this region can be found in the electron data shown in Fig. 4. Note that for the poleward most intense precipitation region the electron energy extends rather continuously from high to low energies in contrast to the region equatorward of this. The lower energy part is probably due to a localised acceleration of ionospheric electrons by the Alfvén wave electric field. Similar observations of dispersive electron fluxes which often are located near auroral arc boundaries, have been presented by Mc Fadden et al. (1986), Gelpi and Bering (1984) and Ivchenko et al. (1999).

\subsection{Summary of observations}

Figure 7 presents a summary of the Astrid-2, Polar and ground-based observations obtained around 22:22 UT. The Astrid-2 electric field data are plotted as vectors and the distribution of field-aligned currents are plotted as squares, open and closed squares corresponding to upward and downward currents, respectively, along the footpoint of the Astrid-2 trajectory. Contours representative of the maximum auroral luminosity inferred from Fig. 1 are shown in the background. The potential contours (dotted lines) are drawn to be consistent with the Astrid-2 and STARE electric field data, and with the direction of the electrojets inferred from the magnetometer data from Greenland, northern Scandinavia, Bjørnøya and Svalbard. An independent check that the inferred convection pattern is realistic is given by the excellent agreement with the convection pattern deduced from SuperDARN radar observations for this particular event as shown in Fig. 8. A careful inspection of a series of SuperDarn convection patterns derived for various times (from $30 \mathrm{~min}$ prior to and 30 min after the Astrid- 2 crossing) shows the same qualitative features as the pattern shown in Fig. 8, which was obtained using data between 22:06 and 22:08 UT. Though this is about 11 min prior to the Astrid-2 crossing, we chose this pattern since the backscatter signal for this time was much stronger and thus allowed a more reliable fitting than was the case for the data from around the Astrid- 2 crossing. The weakening in the backscatter signal, and thus the electric field, is also consistent with the westward electrojet intensification and the electric field (inferred from the STARE data) decrease between between 22:15 and 22:23 UT (Figs. 2a and b) caused by a conductivity increase between these times. The gap in the midnight auroral distribution is shown colocated with the nightside convection throat, in between the dawn and dusk convection cells.

\section{Discussion}

The nightside auroral bulge represents the largest auroral feature of the midnight region. As pointed out in the introduction a fundamental question related to this large-scale auroral feature is to what extent the dawn and dusk convection cells are connected to each other by a large-scale electrojet closure current, such as the substorm current wedge (McPherron et al., 1973). The current wedge, often described as a Cowling current concentrated in a high conductivity channel, is believed to be fed by downward distributed field-aligned currents in the morning convection cell and linked to an upward, 
more localised current in the head of the surge (Inhester et al., 1981; Opgenoorth et al., 1983). Characteristic of the Cowling current model applied to the auroral bulge is that the ionospheric conductivity, represented by $\Sigma_{P}$ and $\Sigma_{H}$, and the $\Sigma_{H} / \Sigma_{P}$ ratio (which increases with increasing characteristic energy of the precipitating electrons) is strongly enhanced within the current channel as compared to the ambient plasma; that a southward polarisation electric field is formed to maintain current continuity for the meridional currents across the channel; and that a strong westward current is formed with contributions from both the initial Pedersen current (driven by the westward convection electric field) and from the secondary Hall current (driven by the polarisation electric field) so that the total current typically becomes substantially larger than the Pedersen current.

Often this model is applied on a large scale, of the size of a substantial fraction of the width of the bulge (see Weimer et al., 1994) although it is clear that the region which best fulfills the conductivity criteria is often the poleward edge of the auroral bulge. This can be seen, e.g., in the generic picture of the auroral bulge presented by Fujii et al.(1994) which is based on a large number of observations of the nightside auroral distribution by the Dynamics Explorer UV imager. As shown by Fujii et al.(1994) and Marklund et al. (1998) an intense southward electric field accompanied by a downward field-aligned current is often found to be located immediately poleward of the bulge. This current is closed by southward Pedersen currents feeding part of the upward currents in the intense poleward part of the auroral bulge. Furthermore, this region of high conductivity is associated with a westward Hall current and not a Cowling current.

For the particular case studied here, intense electrojet activity was observed simultaneously in the dusk and dawn convection cells as inferred from the magnetometer data from the Greenland and northern Scandinavia-Bjørnøya-Svalbard networks, westward and eastward of the Astrid-2 trajectory. The electrojet activity was clearly associated with persistent and extensive nightside auroral activity (see Fig. 1) but not necessarily with a conventional substorm. No efficient connection for the electrojet currents exists between the dawn and dusk convection cells, because of the low conductivity associated with the gap in the auroral distribution and the absence of a polarisation electric field (as evidenced from the almost constant westward electric field observed by Astrid2). There is a connection by westward Pedersen currents over the convection throat, which is most intense in the narrow region near the poleward edge. However, for a typical Hall to Pedersen conductivity of 2.0 , the Pedersen conductivity is five times lower than the Cowling conductivity and thus the Pedersen current is not a very efficient means of connecting the dawn and dusk cell currents.

The region near the poleward boundary was found to be associated with a series of tangential electric field reversals, intense precipitation at both high and low energies, Alfvén wave activity, a density cavity and an upward field-aligned current. The upward current, sandwiched between downward field-aligned currents located on each side of the strip,

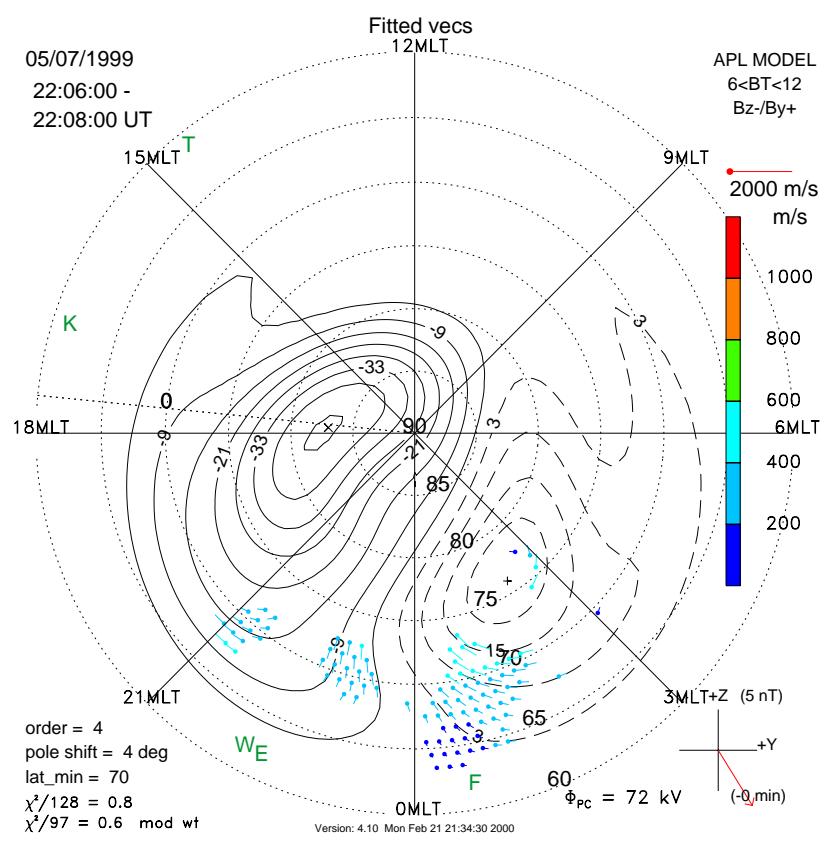

Fig. 8. Instantaneous nightside convection pattern derived from $\mathrm{Su}-$ perDARN observations between 22:06:00 and 22:08:00 UT on 7 May 1999. Note the good agreement with the convection pattern derived from Astrid-2, STARE and the ground-based magnetometer data.

was in this case found to be closed by converging Hall currents. The reversal in the tangential component of the electric field at the poleward auroral boundary and the associated closure by Hall currents is unusual but related to Astrid-2's location near the western edge of the dawn convection cell.

For this event it thus appears that the dawn and dusk cells were not connected by a large-scale current of the type of the substorm current wedge but only by a rather weak Pedersen current flowing in the poleward part of the oval. Whether this represents an exceptional case or whether it may be representative also of other auroral bulge events, remains to be investigated further. The long-lasting presence of nightside auroral activity and the fairly constant level of the AE index around the time of the Astrid- 2 crossing imply that the event treated here did not possess any clear substorm signatures. Nevertheless, this event as well as the event treated by Marklund et al. (1998) clearly illustrates the difficulties in applying the Cowling current model to the electrodynamics of the auroral bulge.

\section{Summary and conclusions}

Multi-satellite and ground-based observations have been presented of the nightside auroral bulge in the middle of the nightside convection throat. This region, located in between the dusk- and dawn convection cells, is found to be associated with a gap in the auroral luminosity distribution observed by the Polar UV-imager and consistent with the relatively low fluxes of energetic electrons observed by Astrid-2. 
From the equatorward boundary to the poleward boundary of the oval the electric field remained strictly westward except for a localised region of tangential electric field reversals near the polar cap boundary. If we assume that the electric field observed by Astrid-2 is representative also for the ionospheric electric field (i.e. that no potential drops existed below $1000 \mathrm{~km}$ ) this implies that no polarisation electric fields are generated to drive an enhanced Cowling current across the gap. Instead the intense electrojets observed within the dusk and dawn convection cells were essentially separated from each other and current closure was maintained locally by upward and downward FACs. The region of tangential electric field reversal near the polar cap boundary, is associated with intense Alfvén activity $(0.4 \mathrm{~Hz}$ oscillations in the electric and magnetic fields and field-aligned fluxes of $\approx 100$ $\mathrm{eV}$ electrons of ionospheric origin) and with an upward fieldaligned current sandwiched between two downward current sheets. The fact that the ionospheric closure currents, associated with this triple field-aligned current sheet, are Hall currents and not Pedersen currents or a combination of the two, is related to the structure being located near the convection throat at the western edge of the dawn convection cell. The main implications of the results presented for this event is that no intense Cowling current was floating between the dawn and dusk sector of the oval, either at large scales (of the size of a significant fraction of the oval width) or at small scales, such as within the narrow region of enhanced conductivity near the poleward oval boundary. Similar to the conclusions made here Marklund et al. (1998) found that the data from a crossing through the head and wake of a WTS were incompatible with the Cowling current model and that the surge current was, to a large extent, closed locally rather than remotely.

Acknowledgements. The authors are grateful to the large number of people who have contributed to the success of the Astrid-2 project. Special thanks to Jürgen Watermann, Danish Meteorological Institute, and C.R. Clauer, University of Michigan, for providing the Greenland magnetometer data. We also want to acknowledge the fruitful collaboration with Olle Norberg at the Swedish Institute of Space Physics, Kiruna and with David Winningham at the Southwest Research Institute, San Antonio, who provided the MEDUSA particle data; Fritz Primdahl at the Danish Space Research Institute, who provided the magnetometer sensor and performed the calibration of the magnetometer instrument; Bengt Holback at the Swedish Institute of Space Physics, Uppsala for providing the Linda plasma density data; Lars Blomberg, Stefan Eriksson, Nickolay Ivchenko, Per-Arne Lindqvist, and Bengt-Harald Nilsson at the Alfvén Laboratory for their important contributions to the software development; Lars Bylander, Ola Carlström, Sverker Christenson and Göran Olsson for their eminent work in building the EMMA instrument. This project was supported by the Swedish National Space Board and managed and operated by the Swedish Space Corporation under contract from the Swedish National Space Board.

Topical Editor G. Chanteur thanks P. L. Rothwell and O. Amm for their help in evaluating this paper.

\section{References}

Amm, O., Improved electrodynamic modeling of an omega band and analysis of its current system, J. Geophys. Res., 101, 2677, 1996.

Akasofu, S.-I., Meng, C.-I., and Kimball, D. S., The dynamics of the aurora, 4, Polar magnetic substorms and westward traveling surges, J. Atmos. Terr. Phys., 28, 489-496, 1966.

Akasofu, S.-I., Kimball, D. S., and Meng, C.-I., The dynamics of the aurora, 2, Westward traveling surges, J. Atmos. Terr. Phys., 27, 173-187, 1965.

Boström, R., A model of the auroral electrojets. J. Geophys. Res., 69, 4983-4999, 1964.

Fujii, R., Hoffman, R. A., Anderson, P. C., Craven, J. D., Sugiura, M., Frank, L. A., and Maynard, N. C., Electrodynamic parameters in the nighttime sector during auroral substorms, J. Geophys. Res., 99, 6093-6112, 1994.

Gelpi, C. G. and Bering, E. A., The plasma wave environment of an auroral arc 2. ULF waves on an auroral arc boundary, J. Geophys. Res., 89, 10847-10864, 1984.

Inhester, B., Baumjohann, W., Greenwald, R. A., and Nielsen, E., Joint two-dimensional observations of ground magnetic and ionospheric electric fields associated with auroral zone currents, 3 , Auroral zone currents during the passage of a westward traveling surge, J. Geophys., 49, 155-162, 1981.

Ivchenko, N., Marklund, G., Lynch, K., Pietrowski, D., Torbert, R., Primdahl, F., and Ranta, A., Quasiperiodic oscillations at the edge of an auroral arc by auroral turbulence 2, Geophys. Res. Lett., 26, 3365-3368, 1999.

Kamide, Y. and Akasofu, S.-I., The auroral electrojet and global auroral features, J. Geophys. Res., 80, 3585, 1975.

Kan, J. R., Williams, R. L., and Akasofu, S.-I., A mechanism for the westward traveling surge during substorms, J. Geophys. Res., 89, 2211, 1984.

Marklund, G. T., Raadu, M. A., and Lindqvist, P.-A., Effects of Birkeland current limitation on high-latitude convection patterns, J. Geophys. Res., 90, 10864-10874, 1985.

Marklund, G. T., Karlsson, T., Blomberg, L. G., Lindqvist, P.-A., Fälthammar, C.-G., Johnson, M. L., Murphree, J. S., Andersson, L., Eliasson, L., Opgenoorth, H. J., and Zanetti, L. J., Observations of the electric field fine structure associated with mediumand large-scale auroral spirals, J. Geophys. Res., 103, 41254144, 1998.

McFadden, J. P., Carlson, C. W., and Boehm, M., Field-aligned electron precipitation at the edge of an arc, J. Geophys. Res., 91, 1723-1730, 1986.

McPherron, R. L., Russel, C. T., and Aubry, M. P., Satellite studies of magnetospheric substorms on 15 August 1968, 9. Phenomenological model for substorms, J. Geophys. Res., 78, 3131, 1973.

Opgenoorth, H. J., Pellinen, R. J., Baumjohann, W., Nielsen, E., Marklund, G., and Eliasson, L., Three dimensional current flow and particle precipitation in a westward travelling surge (observed during the Barium-GEOS rocket experiment), J. Geophys. Res., 88, 3138-3152, 1983.

Pulkkinen, T. I., Baker, D. N., Frank, L. A., Sigwarth, J. B., Pulkkinen, H. J., Greenwald, R., Friis-Christensen, E., Mukai, T., Nakamura, R., Singer, H., Reeves, G. D., and Lester, M., Two substorm intensifications compared: onset, expansion, and global consequences, J. Geophys. Res., 103, 15, 1998.

Rothwell, P. L., Silevitch, M. B., and Block, L. P., A model for the propagation of the westward travelling surge, J. Geophys. Res., 89, 8941-8948, 1984. 
Rothwell, P. L., Silevitch, M. B., and Block, L. P., Pi 2 pulsations and the westward traveling surge, J. Geophys. Res., 91, 69216928,1986

Weimer, D. R., Craven, J. D., Frank, L. A., Hanson, W. B., May- nard, N. C., Hoffman, R. A., and Slavin, J. A., Satellite measurements through the center of a substorm surge, J. Geophys. Res., 99, 23639-23649, 1994. 